\title{
Antioxidant Properties of Capsule Dosage Form From Mixed Extracts of Garcinia Mangostana Rind and Solanum Lycopersicum Fruit
}

\author{
Mahalul Azam¹, Willy Tirza Eden², , Arulita Ika Fibriana ${ }^{1}$, Sri Ratna Rahayu ${ }^{1}$ \\ 1 Public Health Department, Faculty of Sport Science, Universitas Negeri Semarang, Indonesia \\ 2 Chemistry Department, Faculty of Mathematics and Natural Sciences, Universitas Negeri Semarang, Indonesia
}

\begin{abstract}
Several studies showed both Garcinia mangostana L. and Solanum lycopersicum L. have shown important role as natural sources of antioxidant compounds. Hence, capsule supplement from mixed extracts of Garcinia mangostana L. and Solanum lycopersicum L. was prepared. This study aims to investigate the antioxidant properties from the capsules supplement contained with mixed extracts of Garcinia mangostana rind (GMR) and Solanum lycopersicum fruit (SLF). Antioxidant activity of capsule dosage form was measured using DPPH, ABTS, and FRAP assays. In addition, the total phenolic content and total flavonoid content of the capsules preparation were also evaluated. Total phenolic content was $0.7082 \pm 0.1372 \mathrm{mg}$ GAE/capsule and total flavonoid content was $11.7769 \pm 3.9504 \mu \mathrm{g} Q \mathrm{Q} /$ capsule. The strong correlation observed between antioxidant capacity by ABTS method and the total phenolic contents $\left(\mathrm{R}^{2}=0.995, \mathrm{P}<0.05\right)$ indicated that phenolic compounds in capsule preparation related with its antioxidant activity.
\end{abstract}

Keywords: Antioxidant, DPPH, ABTS, FRAP, Garcinia mangostana, Solanum lycopersicum 


\section{INTRODUCTION}

Antioxidant is a molecule that has the ability to protect organisms from damage caused by free radical-induced oxidative stress. Oxidative stress is considered to be linked with numerous degenerative diseases such as cancer, cardiovascular disease, Alzheimer's disease and Parkinson [1-3]. Human body can balance the oxidative state by synthesizing glutathione and enzymes (e.g., catalase and superoxide dismutase) which produced internally, or taking exogenous antioxidants like the vitamin C, vitamin E, carotenoids, and polyphenols [4-5]. Taking dietary antioxidant supplementation has been found to be a promising method of countering the effects of oxidative stress [6-9]. Natural products began to receive much attention as sources of safe antioxidants nowadays [10-12]. Some species of medicinal plants have antioxidant and pharmacological activities which related to the existence of phenolic compounds [13-14].

Mangosteen (Garcinia mangostana L., family Guttiferae) is known as "the queen of tropical fruits" because of its tasty flavor. The pericarp of mangosteen has been used traditionally by Southeast Asian for treating diarrhea, skin infection and wounds, amoebic dysentery, etc [15-16]. G. mangostana rind (GMR) contains a lot of water soluble antioxidant compounds. Various kinds of xanthones, such as prenylated and oxygenated xanthones in GMR had been proven to have strong antioxidant activity [17-19]. Tomato (Solanum lycopersicum L., family Solanaceae) is one of the most consumed vegetables worldwide. S. lycopersicum fruit (SLF) are considered as important sources of dietary antioxidants, such as carotenoids, in particular $\alpha$-carotene, $\beta$-carotene, lycopene, lutein, and cryptoxanthin [20-21]. Anthocyanins, the flavonoid constituents in highly pigmented fruits including tomato, have been reported to possess potential antioxidant, anti-inflammatory, anticancer, and antidiabetic activity [22-24].

GMR and SLF each has been widely investigated for their antioxidant activities, yet the antioxidant properties of mixed extracts of GMR and SLF has not been reviewed. Due to the widely marketed nutritional supplements containing GMR, we are challenged to create capsule dosage form as supplements prepared from both plant extracts. This study aims to investigate the antioxidant properties from the capsules supplement contained with mixed extracts of G. mangostana rind (GMR) and S. lycopersicum fruit (SLF), also its total phenolic and flavonoid contents. Several methods were applied to measure antioxidant capacity, including 2,2-azinobis (3-ethyl-benzothiazoline-6-sulfonic acid) (ABTS), 2,2-diphenyl1-picrylhydrazyl (DPPH), and ferric reducing antioxidant power (FRAP). 


\section{METHODOLOGY}

\section{Chemical and Reagents}

Aluminium chloride hexahydrate, Folin-Ciocalteu's phenol reagent, ascorbic acid, sodium carbonate, quercetin, and gallic acid were purchased from Merck Millipore. Dimethylsulfoxide (DMSO) and AR grade methanol from Sigma-Aldrich. Aerocyl and amylum manihot for preparation of GMR and SLF capsules were purchased from local industries. The commercial grade solvents were used for extraction.

\section{Plant Material}

The G. mangostana and S. lycopersicum fruit were collected from Gatutkaca, a local Jamu (Indonesian traditional medicine) industry and identified by Eling Purwantoyo, M.Si. (Department of Biology, Universitas Negeri Semarang). The voucher specimen (204579) was deposited at the Biology Laboratory, Department of Biology, Universitas Negeri Semarang, Indonesia.

\section{Preparation of Plant Extracts}

Extraction of G. mangostana and S. lycopersicum using hydroalcoholic solvent was based on previous studies which performed hydroalcoholic extractions to obtain antioxidant compounds [25-26]. The dried pericarp of G. mangostana (1000 g) were macerated using $70 \%$ ethanol/water (1:3) at room temperature for $72 \mathrm{~h}$. After filtration, the filtrate was concentrated followed with the addition of aerocyl ( $30 \mathrm{~g}$ ). From this process, $50 \mathrm{~g}$ of condensed extract was obtained. For the $S$. lycopersicum extract, fresh fruits of tomatoes (1000 g) were crushed and blended using $70 \%$ ethanol/water (1:1). After filtration, the filtrate was concentrated followed with the addition of aerocyl $(20 \mathrm{~g}) .65 \mathrm{~g}$ of condensed tomato extracts were obtained.

\section{Preparation of Capsule Contains Mixed Extracts of GMR and SLF}

The condensed extract of GMR were added with $1500 \mathrm{~g}$ filling agents (amylum manihot) to produce dry powder of GMR extracts ( $1448 \mathrm{~g}$ ). The same procedure was also conducted to the condensed extract of SLF. $850 \mathrm{~g}$ filling agents (amylum manihot) were added to produce dry powder of SLF extracts (774 g). Both dried extracts were mixed at a ratio of GMR:SLF (2:1) and capsulated with number 0 capsule shell (average weight $450 \mathrm{mg} /$ capsule).

\section{DPPH-radical Scavenging Activity Assay}

The diphenyl-2-picrylhydrazyl (DPPH) radical scavenging assay was performed based on the method of Zongo (2010) with slight modification [27]. In the microplate well, 10, 20, 30, 40, $50 \mu \mathrm{L}$ of the capsule powder (50 mg/mL in DMSO) 
or standard solution was mixed with $100 \mu \mathrm{L}$ of the DPPH-radical $(100 \mu \mathrm{g} / \mathrm{mL}$ in methanol) and left to stand at room temperature for $15 \mathrm{~min}$ in the dark. The absorbance was measured at $517 \mathrm{~nm}$. Ascorbic acid (Vitamin C) was used as references. This experiment was conducted in triplicates.

\section{ABTS Assay}

In the ABTS free radical assay, the method of Jemli (2015) was adopted with minor changes [28]. Briefly, ABTS reagent solution was freshly prepared by mixing $2 \mathrm{mM}$ of ABTS solution with $70 \mathrm{mM}$ of potassium persulfate, stored in the dark at room temperature for $16 \mathrm{~h}$ before use. ABTS + solution was then diluted with $80 \%$ methanol to obtain an absorbance reading of $0.700 \pm 0.005$ at $743 \mathrm{~nm}$. The $100 \mu \mathrm{L}$ of sample solution with various concentration was added to $100 \mu \mathrm{L}$ of ABTS solution. The absorbance was measured at $734 \mathrm{~nm}$ after 1 minutes of mixture reaction. All the measurements were carried out three times repetition. A standard curve was obtained by using ascorbic acid standard solution at various concentrations (ranging from 25 to $125 \mathrm{~g} / \mathrm{mL}$ ). The scavenging activity of different concentrations of sample against ABTS radical were also measured to calculate $\mathrm{IC}_{50}$, and the procedure was similar to the DPPH scavenging method described above.

\section{FRAP Assay}

FRAP was measured by spectrophotometric assay as previously described [28]. $100 \mu \mathrm{L}$ of sample at different concentration, $100 \mu \mathrm{L}$ of phosphate buffer $(0.2 \mathrm{M}$, $\mathrm{pH}$ 6.6), and $100 \mu \mathrm{L}$ of potassium ferricyanide $\mathrm{K}_{3} \mathrm{Fe}(\mathrm{CN})_{6}(1 \%)$ were mixed and incubated at $50^{\circ} \mathrm{C}$ for $20 \mathrm{~min}$, to reduce ferricyanide into ferrocyanide. The reaction was stopped by adding $100 \mu \mathrm{L}$ of $10 \%(\mathrm{w} / \mathrm{v})$ trichloroacetic acid followed by centrifugation at $3000 \mathrm{rpm}$ for $10 \mathrm{~min}$. Lastly, $100 \mu \mathrm{L}$ of the top layer was mixed with $100 \mu \mathrm{L}$ of distilled water and $25 \mu \mathrm{L}$ of ferric chloride solution (0.1\%) and the absorbance at $710 \mathrm{~nm}$ was calculated by plotting absorbance against the corresponding sample concentration. All the determinations were performed triplicates. Ascorbic acid (vitamin C) was used as a reference compound.

\section{Total Phenolic Contents}

Folin-Ciocalteu's method with slight modification was applied to determine the total phenolic content [29]. In a 96-well plate, $12 \mu \mathrm{L}$ of capsule powder solutions $(250 \mu \mathrm{g} / \mathrm{mL}$ in DMSO) or standard gallic acid solutions were added, followed by 50 $\mu \mathrm{L}$ of DI water and $12 \mu \mathrm{L}$ of Folin-Ciocalteu (50\%, v/v in DI water). After $10 \mathrm{~min}$, $125 \mu \mathrm{L}$ of $7 \% \mathrm{Na}_{2} \mathrm{CO}_{3}$ and $100 \mu \mathrm{L}$ of DI water were added. The mixture was allowed to stand for $15 \mathrm{~min}$ at $45^{\circ} \mathrm{C}$ and the absorbance was determined at $765 \mathrm{~nm}$. Total phenolic content was calculated from gallic acid standard curve with linear relation of $\mathrm{r}^{2}=0.9727$. Data were expressed as mg of gallic equivalent (GAE) per capsule. 


\section{Total Flavonoid Contents}

In order to investigate the total flavonoid content, a colorimetric method was applied [27]. In a 96-well plate, $100 \mu \mathrm{L}$ of the capsule powder (100 $\mu \mathrm{g} / \mathrm{mL}$ in DMSO) or standard quercetin solutions and $100 \mu \mathrm{L}$ of $2 \% \mathrm{AlCl}_{3}$ in methanol were added and mixed thoroughly. The reaction mixture was kept at room temperature for 15 min and the absorbance was recorded at $435 \mathrm{~nm}$. The total flavonoid content was calculated using quercetin standard curve with linear relation of $\mathrm{R}^{2}=0.9936$. Data were expressed as mg quercetin equivalent (QE) per capsule.

\section{RESULT AND DISCUSSION}

According to previous studies, G. mangostana rind contains phytochemicals such as xanthones, terpenes, anthocyanins, tannins, and phenols, which exert numerous biological effects, including antioxidant activity [30-31]. It is believed that antioxidants can help to overcome oxidative damage in human body, which is associated with many degenerative diseases such as atherosclerosis, coronary heart diseases, aging, and cancer [32-33]. S. lycopersicum fruit, which is being widely consumed either fresh or processed in products, possess carotenoids, such as lycopene and $\beta$-carotene that are apparently the main tomato micro constituents that responsible for the effect of tomato product on antioxidant activity [34]. Different solvent was used in the extraction of GMR and SLF. The extraction of GMR and SLF by using 70\% ethanol/water 1:3 and 1:1, respectively, was conducted according to the polarity of major compounds contained in GMR, which is xanthone, and SLF, which is carotenoid. In this study, the antioxidant activity of capsule dosage form prepared from mixed extracts of GMR and SLF was being determined.

\section{Total Phenolic Contents}

It is important to measure the total phenolic compounds correctly in such medicinal plants, the better to assess their antioxidant capacity. Under the basic reaction conditions, a phenol loses an $\mathrm{H}^{+}$ion to produce a phenolate ion, which reduces Folin-Ciocalteu reagent [35]. The change is monitored spectrophotometrically. Results of Total Phenolic Contents (TPC) determination by FolinCiocalteau method are summarized in Table 1. The greater amount signifies the presence of different constituents having phenolic moiety in their structures. The phenolic content with respect to gallic acid was found to be $0.7082 \pm 0.1372$ (mg Gallic Acid Equivalent/capsule). 
Table 1. The Total Phenolic Content of Capsule Preparation from Mixed Extract of G. mangostana rind (GMR) and S. lycopersicum fruit (SLF)

\begin{tabular}{|c|c|c|c|c|}
\hline Sample & Equation & $\mathbf{R}^{2}$ & $\begin{array}{c}\text { TPC } \\
\text { (mg GAE/capsule) }\end{array}$ & $\begin{array}{c}\text { Mean TPC } \\
\text { (mg GAE/capsule) }\end{array}$ \\
\hline $\begin{array}{c}\text { Capsule } \\
\text { (1 }{ }^{\text {st }} \text { repetition) }\end{array}$ & $y=4.1289 x+0.029$ & 0.9863 & 0.8588 & \\
\hline $\begin{array}{c}\text { Capsule } \\
\text { (2nd repetition) }\end{array}$ & $y=4.07 x+0.0346$ & 0.9987 & 0.6643 & \\
\hline $\begin{array}{c}\text { Capsule } \\
\left.\text { (3 }{ }^{\text {rd }} \text { repetition }\right)\end{array}$ & $\begin{array}{c}y=3.8011 x+ \\
0.0854\end{array}$ & 0.9596 & 0.6241 & $0.7082 \pm 0.1372$ \\
\hline $\begin{array}{c}\text { Capsule } \\
\text { (4th repetition) }\end{array}$ & $\begin{aligned} y= & 4.2799 x+ \\
& 0.0458\end{aligned}$ & 0.9438 & 0.7974 & \\
\hline $\begin{array}{c}\text { Capsule } \\
\text { (5 } \\
\text { th } \\
\text { repetition) }\end{array}$ & $y=4.2376 x-0.0213$ & 0.9343 & 0.9564 & \\
\hline
\end{tabular}

\section{Total Flavonoid Contents}

The Total Flavonoids Content (TFC) of the capsule dosage form was determined by a colorimetric assay using quercetin as standard (Table 2). The greater amount signifies the presence of more flavonoids moieties in the constituents. The flavonoid content with respect to quercetin was found to be $11.7769 \pm 3.9504$ ( $\mu$ g Quercetin Equivalent/capsule).

Table 2. The Total Flavonoid Content of Capsule Preparation from Mixed Extract of G. mangostana rind (GMR) and S. lycopersicum fruit (SLF)

\begin{tabular}{|c|c|c|c|c|}
\hline Sample & Equation & $\mathbf{R}^{2}$ & 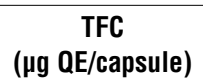 & $\begin{array}{c}\text { Mean TPC } \\
\text { ( } \mu \mathrm{g} \text { QE/capsule) }\end{array}$ \\
\hline $\begin{array}{c}\text { Capsule } \\
\text { (1 } 1^{\text {st }} \text { repetition) }\end{array}$ & $y=0.0155 x+0.1738$ & 0.9453 & 11.5552 & \\
\hline $\begin{array}{c}\text { Capsule } \\
\text { (2 }\end{array}$ & $y=0.0162 x+0.1863$ & 0.9885 & 6.4782 & \\
\hline $\begin{array}{c}\text { Capsule } \\
\text { (3 } 3^{\text {rd }} \text { repetition) }\end{array}$ & $y=0.0156 x+0.175$ & 0.9726 & 12.8523 & $11.7769 \pm 3.9504$ \\
\hline $\begin{array}{c}\text { Capsule } \\
\text { (4th } \\
\text { repetition })\end{array}$ & $y=0.0173 x+0.1334$ & 0.9780 & 17.4097 & \\
\hline $\begin{array}{c}\text { Capsule } \\
\text { (5 }\end{array}$ & $y=0.0154 x+0.1524$ & 0.9752 & 10.5889 & \\
\hline
\end{tabular}

Most antioxidant activities from plant sources correlate with phenolic and flavonoid contents. The next section discuss about the antioxidant activity and the correlation between phenolic and flavonoid contents; and antioxidant activity. 


\section{Antioxidant Activity}

In this study, the antioxidant activities were determined by in vitro assays, including 2,2-azinobis (3-ethyl-benzothiazoline-6-sulfonic acid) (ABTS), 2,2-diphenyl-1-picrylhydrazyl (DPPH), and ferric reducing antioxidant power (FRAP). All three assays are based on the reaction of electron transfer, where the color change would serve as an indication of the antioxidant's ability to reduce radicals [36].

Table 3. $I_{50}$ Values of Capsule Preparation from Mixed Extract of G. mangostana rind (GMR) and S. lycopersicum fruit (SLF)

\begin{tabular}{ccc}
\hline Assays & Sample $(\mathrm{mg} / \mathrm{mL})$ & $\begin{array}{c}\text { Positive control } \\
(\text { Vitamin } \mathbf{C})(\boldsymbol{\mu g} / \mathbf{m L})\end{array}$ \\
\hline DPPH & $5.8837 \pm 1.4586$ & $184.7211 \pm 9.1777$ \\
ABTS & $6.8098 \pm 2.8832$ & $83.6069 \pm 8.2220$ \\
FRAP & $13.7393 \pm 2.3856$ & $80.6294 \pm 9.5560$ \\
\hline
\end{tabular}

Values represent means \pm SD (standard deviations) for triplicates experiment

As summarized in Table 3, the measurement using DPPH method resulted the lowest $\mathrm{IC}_{50}$ for capsule dosage form (sample), whereas FRAP method resulted the lowest $\mathrm{IC}_{50}$ for standard reference (ascorbic acid). Therefore, it is possible that capsule contain mixed extracts of SLF and GMR exhibit different antioxidant mechanism than ascorbic acid. Vitamin $\mathrm{C}$ acts as a scavenger of ROS and by one-electron reduction of lipid hydroperoxyl radicals via the vitamin $\mathrm{E}$ redox cycle, hence it has the ability to protect against lipid peroxidation (radical chain reaction) [37-39].

Since the capsules were prepared from mixing $50 \mathrm{~g}$ of GMR extracts and $65 \mathrm{~g}$ of SLF extracts and filling agents, we calculated the estimation of the $\mathrm{IC}_{50}$ value of each extracts that may contribute to the antioxidant activity (Table 4).

Table 4. Estimation of $\mathrm{IC}_{50}$ Value of Each Extracts

\begin{tabular}{ccc}
\hline Assays & GMR extract $(\boldsymbol{\mu g} / \mathbf{m L})$ & SLF extract $(\boldsymbol{\mu g} / \mathbf{m L})$ \\
\hline DPPH & 200.10 & 100.50 \\
ABTS & 231.60 & 115.80 \\
FRAP & 467.27 & 233.63 \\
\hline
\end{tabular}


It has been proposed that samples with $\mathrm{IC}_{50}$ lower than $50 \mu \mathrm{g} / \mathrm{mL}$ are very strong antioxidants, with $50-100 \mu \mathrm{g} / \mathrm{mL}$ are strong, with $100-250 \mu \mathrm{g} / \mathrm{mL}$ are moderate, with $\mathrm{IC}_{50}$ greater than $250 \mu \mathrm{g} / \mathrm{mL}$ are weak antioxidants, and with $\mathrm{IC}_{50}$ greater than $500 \mu \mathrm{g} / \mathrm{mL}$ are inactive [40]. Meanwhile, Molyneux (2004) stated that $\mathrm{IC}_{50}$ of 200$1000 \mu \mathrm{g} / \mathrm{mL}$ is less active but still has an antioxidant potential [41]. Thus, generally, GMR and SLF extracts are considered to have moderate antioxidant activity.

In addition, we conducted the correlation analysis of the values of total antioxidant capacity obtained by three assay methods, also the correlation analysis of the TFC and TPC to the antioxidant capacity. As shown in Table 5, TPC and ABTS assay indicated a strong correlation $\left(\mathrm{R}^{2}=0.995\right)$.

Table 5. Correlation Coefficient $\left(\mathrm{R}^{2}\right)$ among Antioxidant Assays and Total Phenolic and Flavonoid Contents

\begin{tabular}{cccc}
\hline & DPPH & ABTS & FRAP \\
\hline ABTS & 0.182 & - & - \\
FRAP & 0.395 & 0.190 & - \\
TPC & 0.133 & $0.995^{\star}$ & 0.255 \\
TFC & 0.358 & 0.221 & 0.217 \\
\hline
\end{tabular}

${ }^{*}$ Correlation is significant at $\mathrm{P}<0.05$

The strong correlation between TPC and antioxidant capacity of ABTS assay shown that phenolic content of GMR and SLF capsule was responsible for its antioxidant activity. The present study revealed that strong correlation between total phenolic and ABTS assay was in agreement with previous studies [42-44]. The ABTS assay is based on the generation of a blue/green $\mathrm{ABTS}^{++}$, which is applicable to both hydrophilic and lipophilic antioxidant systems. The previous investigation by Floegel (2011) stated that the high-pigmented and hydrophilic antioxidants were better reflected by ABTS assay [42]. There was no correlation between antioxidant activity as determined by DPPH, ABTS, and FRAP assays $\left(\mathrm{R}^{2}=0.182\right.$ to $\left.0.395, \mathrm{P}>0.05\right)$. This might be due to the potential of an antioxidant against free radicals of DPPH and ABTS and inevitably does not equal with its ability to reduce ferric to ferrous [45].

Therefore, based on the finding of this study, capsule dosage form containing mixed extracts of GMR and SLF possesses in vitro antioxidant potential. Capsule dosage form of mixed GMR and SLF extracts would be an interesting subject to be further investigated for its in vivo antioxidant activity study in animal models. Further experiments needed to obtain a standardized natural-based supplement for combating harmful effects of oxidative stress in human body. 


\section{ACKNOWLEDGEMENT}

This research is supported by grant funds under PDUPT program (DIPA 042.01.2.400899/2019) by the Directorate of Research and Public Service, Ministry of Research, Technology, and Higher Education, Republic of Indonesia. The authors also gratefully acknowledge support from the Production Laboratory of PJ Gatutkaca (Hj Widatik and Dr. Anton B.H.) and all other parties involved in this study. 


\section{REFERENCES}

1. Salehi, B.; Martorell, M.; Arbiser, J.; Sureda, A.; Martins, N.; Maurya, P.; Sharifi-Rad, J. Antioxidants: Positive or Negative Actors?. Biomolecules. 2018, 8(4), 124.

2. Kurutas, E. B. The Importance of Antioxidants which Play the Role in Cellular Response Against Oxidative/Nitrosative Stress: Current State. Nutr. J. 2015, 15(1), 1-22.

3. Liu, Z.; Zhou, T.; Ziegler, A. C.; Dimitrion, P.; Zuo, L. Oxidative Stress in Neurodegenerative Diseases: From Molecular Mechanisms to Clinical Applications. Oxidative Med. Cell. Longevity. 2017, 1-11.

4. Pawar, R.K.; Bhagure, G.R.; Chavan, R.P. Antioxidants and Their Role in Nurture Human Life and Industry: A Review, Int. J. Chem. Stud. 2016, 4(3), 22-26.

5. Xu, D.P.; Li, Y.; Meng, X.; Zhou, T.; Zhou, Y.; Zheng, J.; Li, H.B. Natural Antioxidants in Foods and Medicinal Plants: Extraction, Assessment and Resources. Int. J. Mol. Sci. 2017, 18(1), 96.

6. Kasote, D. M.; Katyare, S. S.; Hegde, M. V.; Bae, H. Significance of Antioxidant Potential of Plants and its Relevance to Therapeutic Applications. Int. J. Biol. Sci. 2015, 11(8), 982-991.

7. Tan, B. L.; Norhaizan, M. E.; Liew, W.P.P.; Sulaiman Rahman, H. Antioxidant and Oxidative Stress: A Mutual Interplay in Age-Related Diseases. Front. Pharmacol. 2018, 9, 1162.

8. Tan, B. L.; Norhaizan, M. E. Scientific Evidence of Rice By-Products for Cancer Prevention: Chemopreventive Properties of Waste Products from Rice Milling on Carcinogenesis In Vitro and In Vivo. BioMed Res. Int. 2017, 1-18.

9. Panche, A.N.; Diwan, A.D.; Chandra, S.R. Flavonoids: an Overview, J. Nutr. Sci. 2016, 5(47), 1-15.

10. Cardoso, S. M. Special Issue: The Antioxidant Capacities of Natural Products Antioxidants of Natural Plant Origins: From Sources to Food Industry Applications. Molecules. 2019, 24(3), 492.

11. Lourenço S. C.; Moldão-Martins, M.; Alves, V.D. Antioxidants of Natural Plant Origins: From Sources to Food Industry Applications. Molecules, 2019, 24, 4132.

12. Ricordi, C.; Garcia-Contreras, M.; Farnetti, S. Diet and Inflammation: Possible Effects on Immunity, Chronic Diseases, and Life Span. J. Am. Coll. Nutr. 2015, 34(1), 10-13.

13. Tungmunnithum, D.; Thongboonyou, A.; Pholboon, A.; Yangsabai, A. Flavonoids and Other Phenolic Compounds from Medicinal Plants for Pharmaceutical and Medical Aspects: An Overview. Medicines. 2018, 5(3), 93.

14. Ulewicz-Magulska, B.; Wesolowski, M. Total Phenolic Contents and Antioxidant Potential of Herbs Used for Medical and Culinary Purposes, Plant Foods Hum. Nutr. 2019, 74, 61-67.

15. Karim, N.; Tangpong, J.; Biological Properties in Relation to Health Promotion Effects of Garcinia Mangostana (Queen of Fruit): A Short Report. J. Health Res. 2018, 32(5), 364-370.

16. Pierce, S. C. A Thai Herbal, Findhorn Press: Scotland, 2003: 118.

17. Francik R.; Szkaradek, N.; Zelaszczyk, D.; Marona, H. Antioxidant Activity of Xanthone Derivatives, Acta Pol. Pharm. 2016, 73(6), 1505-1509.

18. Tjahjani, S; Widowati, W; Khiong, K; Suhendra, A; Tjokropranoto R. Antioxidant Properties of Garcinia mangostana L (Mangosteen) Rind. Procedia Chem. 2014, 13, 198-203.

19. Yang, R.; Li, P.; Li, N.; Zhang, Q.; Bai, X.; Wang, L. Xanthones from the Pericarp of Garcinia mangostana. Molecules. 2017, 22, 683 .

20. Sidhu, V.; Nandwani, D.; Wang, L.; Wu, Y. A Study on Organic Tomatoes: Effect of a Bi- 
ostimulator on Phytochemical and Antioxidant Activities, J. Food Qual. 2017, 1-8.

21. Chaudhary, P.; Sharma, A.; Singh, B.; Nagpal, A. K. Bioactivities of Phytochemicals Present in Tomato. J. Food Sci. Technol. 2018, 55(8), 2833-2849.

22 .Martí, R.; Roselló, S.; Cebolla-Cornejo, J. Tomato as a Source of Carotenoids and Polyphenols Targeted to Cancer Prevention. Cancers. 2016, 8(6), 58.

23. Li, S.; Wu, B.; Fu, W.; Reddivari, L. The Anti-inflammatory Effects of Dietary Anthocyanins against Ulcerative Colitis. Int. J. Mol. Sci. 2019, 20(10), 2588.

24. AL-Ishaq, R.K.; Abotaleb, M.; Kubatka, P.; Kajo, K.; Büsselberg, D. Flavonoids and Their Anti-Diabetic Effects: Cellular Mechanisms and Effects to Improve Blood Sugar Levels. Biomolecules. 2019, 9(9), 430.

25. Carvalho-Silva, R.; Pereira, A. C. F.; Santos Alves, R. P.; Guecheva, T. N.; Henriques, J. A. P.; Brendel, M.; Rios-Santos, F. DNA Protection against Oxidative Damage Using the Hydroalcoholic Extract of Garcinia mangostana and Alpha-Mangostin. Evid.-Based Complement. Altern. Med. 2016, 1-8.

26. Kaneria, M.; Kanani, B.; Chanda, S. Assessment of Effect of Hydroalcoholic and Decoction Methods on Extraction of Antioxidants from Selected Indian Medicinal Plants. Asian Pac. J. Trop. Biomed. 2012, 2(3), 195-202.

27. Zongo, C.; Savadogo, A.; Ouattara, L.; Bassole, H. N.; Ouattara, C. A. T.; Ouattara, A. S.; Barro, N.; Koudou, J.; Traore, A. S.; Polyphenols Content, Antioxidant and Antimicrobial Activities of Ampelocissus grantii (Baker) Planch. (Vitaceae): A Medicinal Plant from Burkina Faso. Int. J. Pharmacol. 2010, 6, 880-887.

28. Jemli, M. E.; Kamal, R.; Marmouzi, I.; Zerrouki, A.; Cherrah, Y.; Alaoui, K. Radical-Scavenging Activity and Ferric Reducing Ability of Juniperus thurifera (L.), J. oxycedrus (L.), J. phoenicea (L.), and Tetraclinis articulate (L.). Adv. Pharmacol. Sci. 2016, 1-6.

29. Panyathep, A.; Chewonarin, T.; Taneyhill, K.; Vinitketkum, U. Antioxidant and Anti-matrix Metalloproteinases Activities of Dried Longan (Euphoria longana) Seed Extract. ScienceAsia. 2013, 39, 12-18.

3o. Ovalle-Magallanes, O.; Eugenio-Pérez, D.; Pedraza-Chaverri, J. Medicinal Properties of Mangosteen (Garcinia mangostana L.): a Comprehensive Update. Food Chem. Toxicol. 2017, 109, 102-122.

31. Suttirak, W.; Manurakchinakorn, S. In Vitro Antioxidant Properties of Mangosteen Peel Extract. J. Food Sci. Technol. 2012, 51(12), 3546-3558.

32. Chaouche, T. M.; Haddouchi, F.; Ksouri, R.; Atik-Bekkara, F. Evaluation of Antioxidant Activity of Hydromethanolic Extracts of Some Medicinal Species from South Algeria. J. Chin. Med. Assoc. 2014, 77, 302-307.

33. Abdel-Daim, M. M.; Zakhary, N. I.; Aleya, L.; Bungău, S. G.; Bohara, R. A.; Siddiqi, N. J. Aging, Metabolic, and Degenerative Disorders: Biomedical Value of Antioxidants. Oxidative Med. Cell. Longev. 2018, 1-2.

34. Bhandari, S. R.; Lee, J. G. Ripening-Dependent Changes in Antioxidants, Color Attributes, and Antioxidant Activity of Seven Tomato (Solanum lycopersicum L.) Cultivars. J. Anal. Methods Chem. 2016, 1-13.

35. Ahmed, D.; Khan, M.; Saeed, R. Comparative Analysis of Phenolics, Flavonoids, and Antioxidant and Antibacterial Potential of Methanolic, Hexanic and Aqueous Extracts from Adiantum caudatum Leaves. Antioxidants. 2015, 4, 394-409. 
36. Huang, D.; Ou, B.; Prior, R.L. The Chemistry behind Antioxidant Capacity Assays. J. Agric. Food Chem. 2005, 53 (6), 1841-1856.

37. Pehlivan, F. E. Vitamin C: An Antioxidant Agent. 2017, Intech Open, doi:10.5772/intechopen.69660

38. Nimse, S. B.; Pal, D. Free Radicals, Natural Antioxidants, and Their Reaction Mechanisms. RSC Adv. 2005, 5(35), 27986-28006.

39. Traber, M. G.; Stevens, J. F. Vitamins C and E: Beneficial Effects from A Mechanistic Perspective. Free Radic. Biol. Med. 2015, 51(5), 1000-1013.

40. Jun, M.; Fu, H. Y.; Hong, J.; Wan, X.; Yang, C. S.; Ho, C. T. Comparison of Antioxidant Activities of Isoflavones from Kudzu Root (Pueraria lobata Ohwi). J. Food Sci. 2003, 68, 2117-2122.

41. Molyneux, P. The Use of the Stable Free Radical Diphenylpicrylhydrazyl for Estimating Antioxidant Activity. SJST, 2004, 26, 211-219.

42. Floegel, A.; Kim, D.O.; Chung, S.J.; Koo, S. I.; Chun, O. K. Comparison of ABTS/DPPH Assays to Measure Antioxidant Capacity in Popular Antioxidant-Rich US Foods. J. Food Compos. Anal. 2011, 24(7), 1043-1048.

43. Dudonne', S.; Vitrac, X.; Coutiere, P.; Woillez, M.; Merillon, J.M. Comparative Study of Antioxidant Properties and Total Phenolic Content of 30 Plant Extracts of Industrial Interest using DPPH, ABTS, FRAP, SOD, and ORAC Assays. J. Agric. Food Chem. 2009, 57, 1768-1774.

44. Samaniego Sanchez, C.; Troncoso Gonzalez, A.M.; Garcia-Parrilla, M.C.; Quesada Granados, J.J.; Lopez Garcia de la Serrana, H.; Lopez Martinez, M.C. Different radical scavenging tests in virgin olive oil and their relation to the total phenol content. Anal. Chim. Acta, 2007, 593, 103-107.

45. Sadeghi, Z.; Valizadeh, J.; Shermeh, O.A.; Akaberi, M. Antioxidant Activity and Total Phenolic Content of Boerhavia elegans (Choisy) Grown in Baluchestan, Iran. Avicenna J. Phytomed, 2015, 5(1): 1-9. 